\begin{tabular}{|c|c|}
\hline \multirow{3}{*}{ 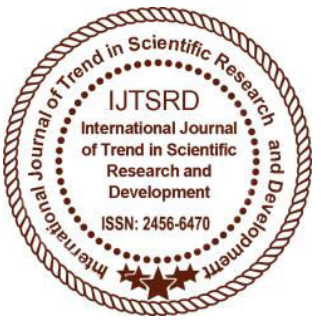 } & $\begin{array}{l}\text { International Journal of Trend in Scientific } \\
\text { Research and Development (IJTSRD) }\end{array}$ \\
\hline & UGC Approved International Open Access Journal \\
\hline & ISSN No: 2456 - 6470 | www.ijtsrd.com | Volume - 1 | Issue - 5 \\
\hline
\end{tabular}

\title{
An Analysis and Study of HAAR Wavelet Based Method for 2D Image Compression
}

\author{
Dr. Chetan R. Dudhagara \\ Assistant Professor, \\ Computer Science Department, \\ N. V. Patel College of Pure and Applied Sciences, \\ Vallabh Vidyanagar, Gujarat, India
}

\section{ABSTRACT}

Now a day, in the era of technology every media is converted into digital media or objects. This digital media is transfer from one place to another place by using the internet for different purposes. The size of these digital media is play major role for transfer over internet. To send or receive the large size of media, it requires high speed bandwidth in internet connection. It also takes more time to transfer this media. It is necessary to reduce the size of these digital objects such as image, text, audio and video. To reduce the size of objects, it is done by using compression methods. There are various compression methods and algorithms are available. This paper represents the discrete haar wavelet transformation for image compression. Many redundancies are available in images. It is used to compress the image. Coding Redundancy, Inter pixel Redundancy and Perceptual Redundancy are used to compress the image.
Keywords: Media, Bandwidth, Internet, Compression, Coding Redundancy, Perceptual Redundancy

\section{INTRODUCTION :}

Wavelet based compression is also known as Discrete Wavelet Transforms (DWT). It treated the image as a signal or wave. The image wavelet compression process consists of the following steps :

$>$ Wavelet Transformation

$>$ Quantization

$>$ Entropy Coding

Below figure shows the block diagram of general and wavelet based image compression and decompression process.

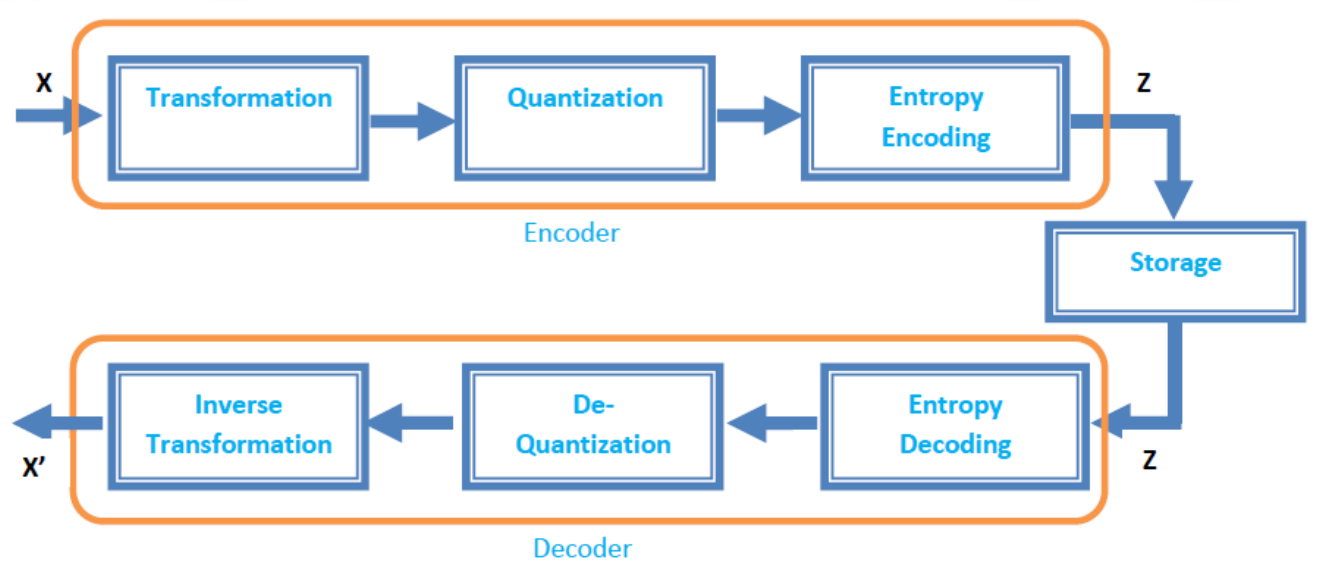

Figure 1: Block Diagram of Compression and Decompression Process 


\section{WAVELET TRANSFORMATION :}

Image wavelet transform is the fast algorithm of two dimensional wavelet transform.

In this transform, first step we perform of transform on all rows. Next, we apply to all columns. These results in four types of coefficients: LL, HL, LH, HH as follows:
For example, the image to be compressed has a dimension of $\mathrm{M}$ rows by $\mathrm{N}$ columns. The approach of the 2-D implementation of the DWT is to perform the one dimensional DWT in row direction and it is followed by a one dimensional DWT in column direction. A two dimensional row and column computation of DWT is display in below figure

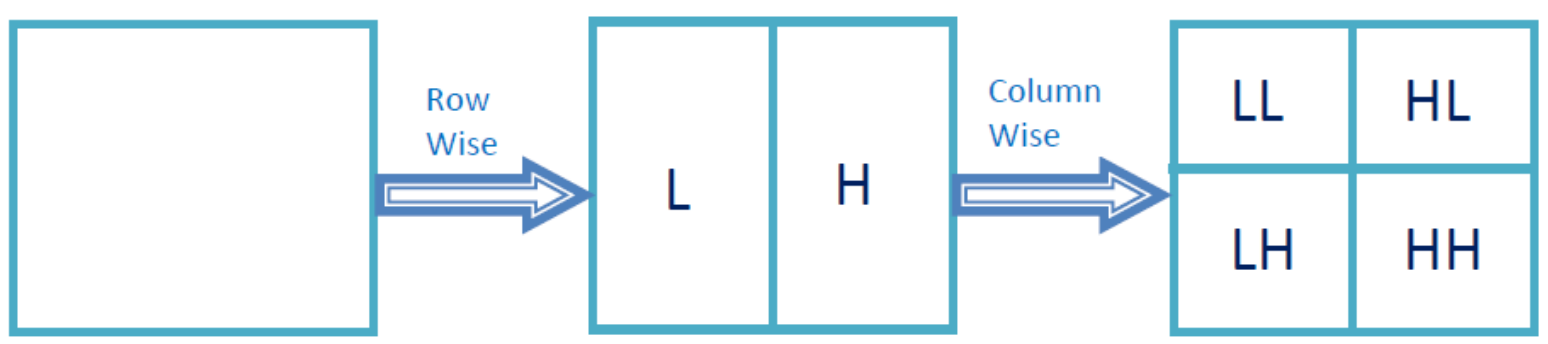

Figure 2: 2D Row and Column DWT

In above figure, $\mathrm{LL}$ is a coarser version of the original image. LL contains the approximation information which is in low frequency. LH, HL, and $\mathrm{HH}$ are the high-frequency sub band containing the detail information.

\section{PERFORMANCE CRITERION :}

The performance of image compression methods is measured by Compression Ratio (CR), Peak Signal to Noise Ratio (PSNR) and elapsed time for the image compression. MSE, RMSE, PSNR and CR are calculating by using the following methods.

\section{Mean Square Error (MSE):}

Mean Square Error (MSE) is used to measure the rate of distortion in the reconstructed image. MSE is define as

$$
M S E=\frac{1}{M * N} \sum_{x=1}^{M} \sum_{y=1}^{N}\left[f(x, y)-f^{\prime}(x, y)\right]^{2}
$$

Where $\mathrm{M} * \mathrm{~N}$ is the size of the original image.

\section{Root Mean Square Error (RMSE) :}

RMSE is define as

\section{RMSE $=\sqrt{M S E}$}

\section{Peak Signal to Noise Ratio (PSNR):}

PSNR is an import measure of image compression. It main purpose of PSNR is to measure the quality of reconstruct image. It is widely used for quality measurement in the area of image compression. It is measured in decibels (dB). Generally, high PSNR indicate high reconstruction quality. PSNR is define as

$$
P S N R=10 \log _{10}\left(\frac{255^{2}}{M S E}\right)
$$

Here 255 is the maximum possible value that can be attained by the image.

\section{Compression Ratio:}

The Compression ratio (CR) is the ratio between the size of the original image and the size of the compressed image. $\mathrm{CR}$ is define as

$$
C R=\frac{n 1}{n 2}
$$

Where $\mathrm{n} 1$ is the number of bits original image and $\mathrm{n} 2$ is the compressed image.

\section{EXPERIMENTAL STUDY :}

Wavelet based image compression algorithm experiment is performed on Peppers.jpg image. This experiment is performing on haar algorithm at 
International Journal of Trend in Scientific Research and Development (IJTSRD) ISSN: 2456-6470 different decomposition level. In our experiment we perform this study up to five different levels. Below images represent the different decomposition level and compressed image.
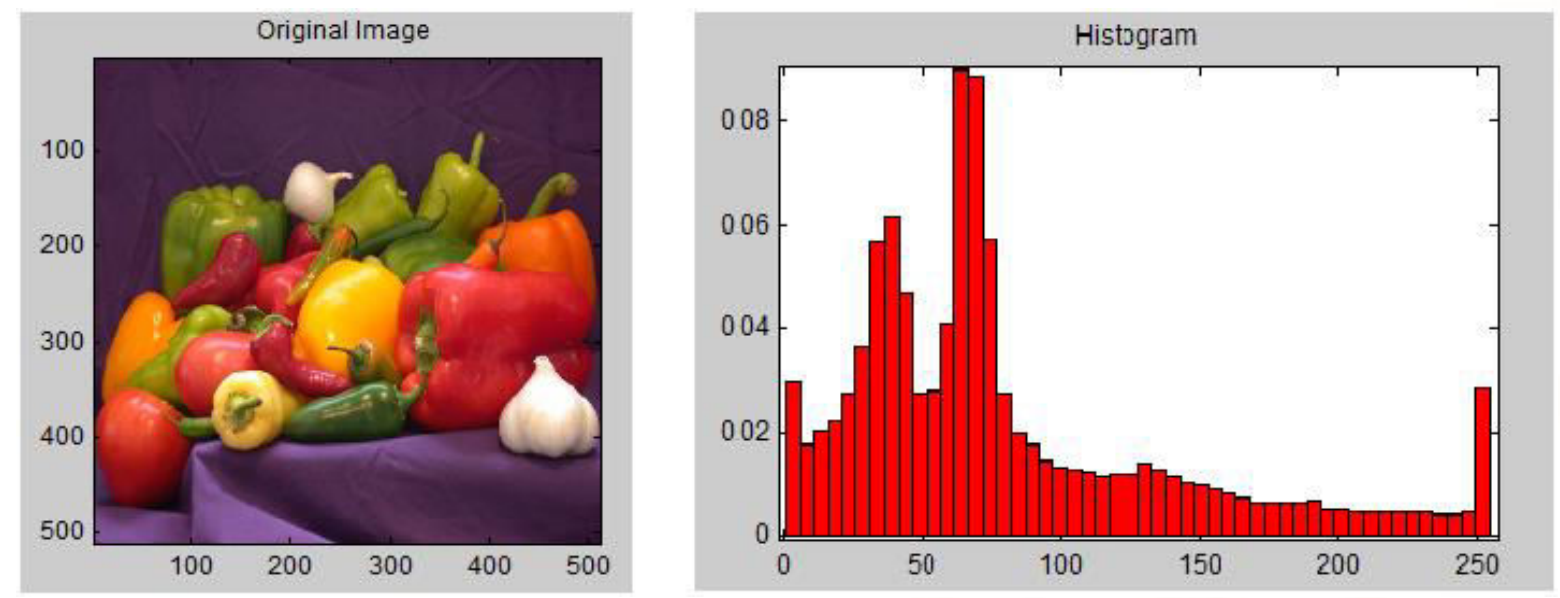

Figure 3: Original Image with Histogram

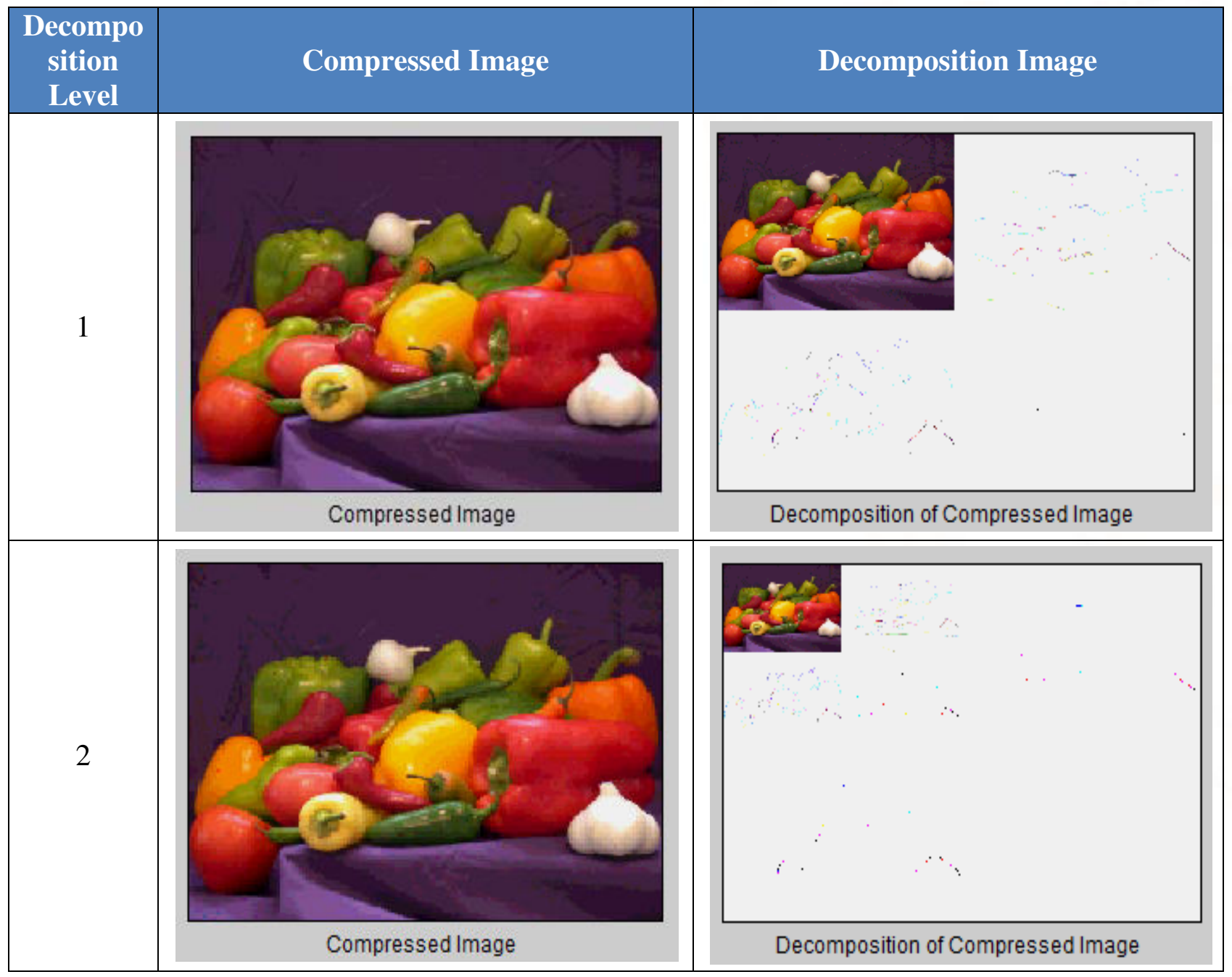


International Journal of Trend in Scientific Research and Development (IJTSRD) ISSN: 2456-6470

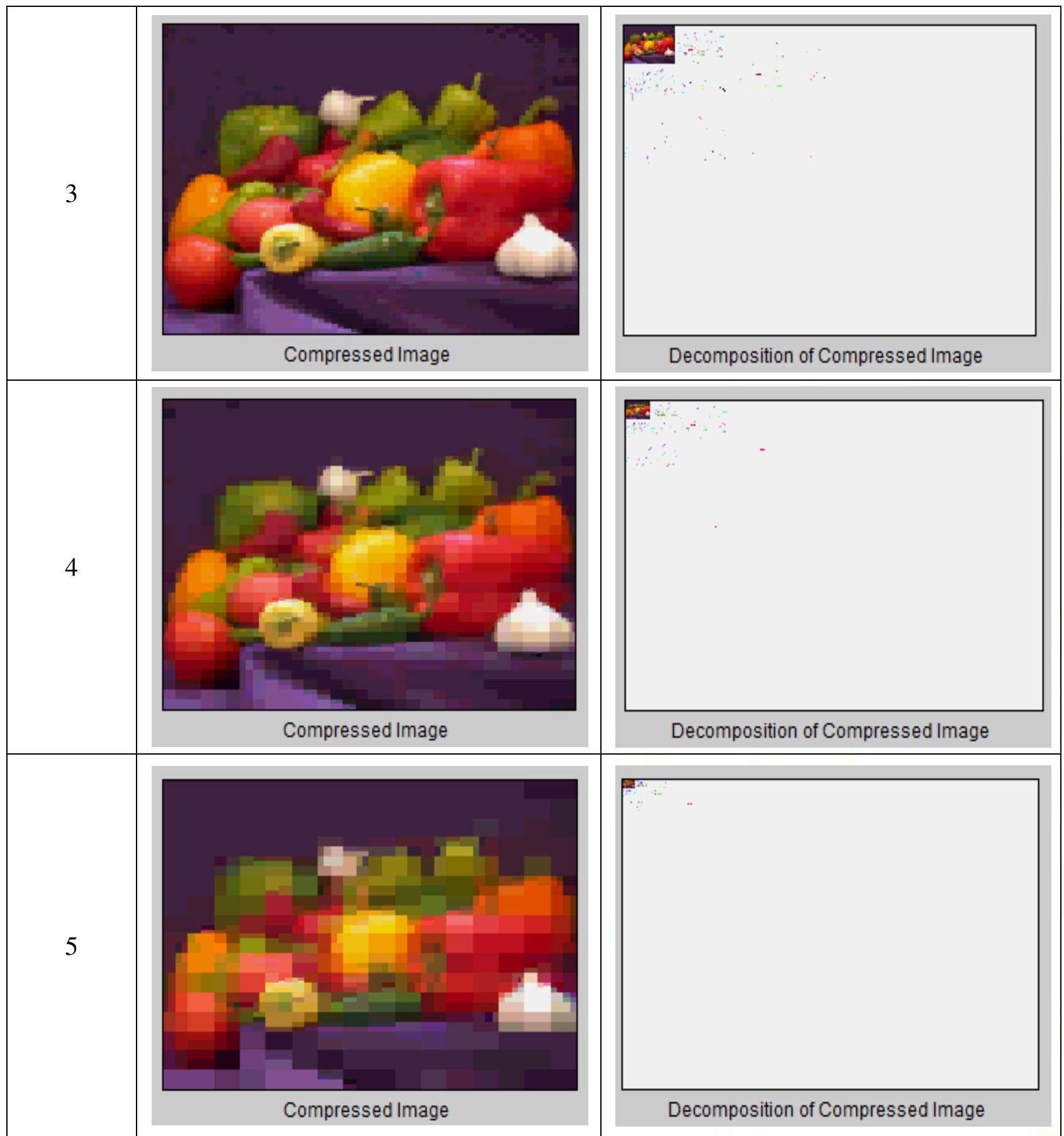

\section{PERFORMANCE ANALYSIS RESULT DISCUSION :}

Below table shows the different wavelet based image compression algorithm at different decomposition level on peppers image.

\begin{tabular}{|c|c|c|c|}
\hline $\begin{array}{c}\text { Decomposition } \\
\text { Level }\end{array}$ & MSE & PSNR & CR (\%) \\
\hline $\mathbf{1}$ & 97.21 & 28.25 & 61.31 \\
\hline $\mathbf{2}$ & 125.6 & 27.14 & 15.85 \\
\hline $\mathbf{3}$ & 181.6 & 25.54 & 4.21 \\
\hline $\mathbf{4}$ & 297.0 & 23.4 & 1.76 \\
\hline $\mathbf{5}$ & 503.5 & 21.11 & 0.33 \\
\hline
\end{tabular}

Table 1: Compression Ratio at different decomposition level 


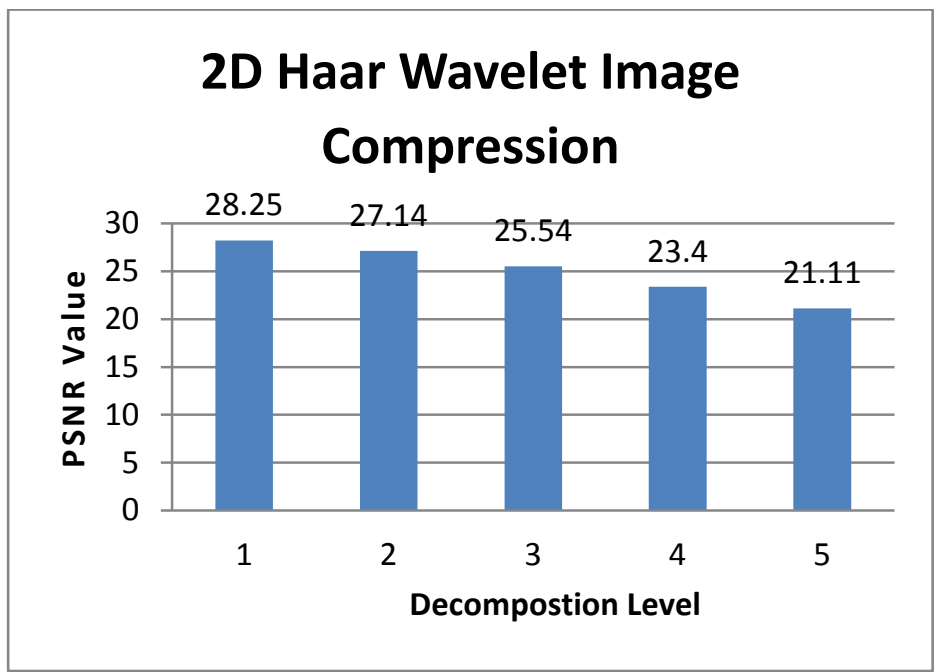

Figure 4: PSNR value at different level

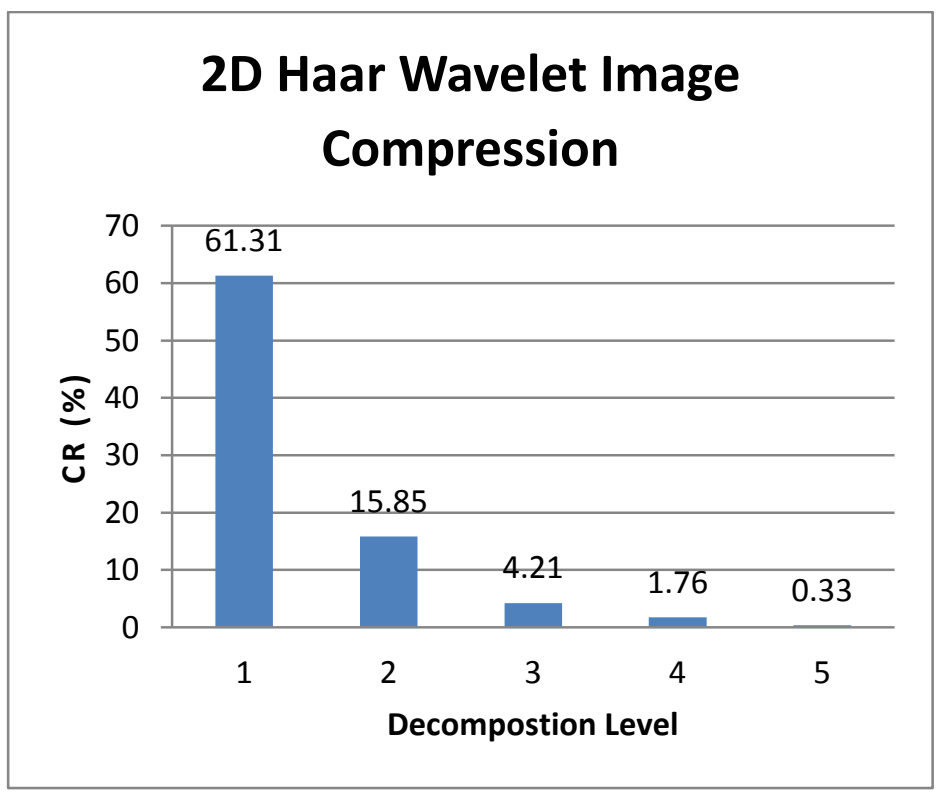

Figure 5: Compression Ratio at different level

\section{CONCLUSION :}

From the experimental study of peppers image of haar wavelet algorithm at different level, it concludes that when you increase the decomposition level, the value of MSE is increased and the value of PSNR is decreased. Finally it concludes that when you increase the decomposition level, the compressed ratio and quality of image is decrease which is shown in above table.

\section{REFERENCES}

1) Kaleka, Jashanbir Singh, Sharma Reecha.,"Comparativ performance analysis of Haar, Symlets and Bior wavelets on image compression using Discrete wavelet Transform”, International journal of Computers and Distributed Systems, Volume 1, Issue 2, August,2012.

2) Kumar, V., V. Sunil., Reddy, M. Indra Sena., "Image Compression Techniques by using Wavelet Transform", Journal of information engineering and applications, Vol 2, No.5, 2012.

3) Sandeep Kaur, Garanpreet Kaur, Dheerendra Singh, "Comparative Analysis of Haar and Coiflet Wavelets using Discrete Wavelet Transform in Digital Image Compression, International Journal of Engineering Research and Applications (IJERA), Vol. 3, Issue 3, May-Jun 2013.

4) Rupinder Kaur, Jagroop Singh, "Comparative Study Of Dwt Based Image Compression Using Haar, Daub \& Coif Wavelets", International Journal of Advance Research In Science And Engineering, Vol. No.3, Issue No.10, October 2014.

5) Monika Rathee, Alka Vij, " Image compression Using Discrete Haar Wavelet Transforms", International Journal of Engineering and Innovative Technology (IJEIT), Volume 3, Issue 12, June 2014.

6) Kharate G. K., Patil V. H., "Color Image Compression Based On Wavelet Packet Best Tree," IJCSI International Journal of Computer Science Issues, Vol. 7, Issue 2, No 3, March 2010.

7) Singh, Sanjeev Chopra, Harmanpreet Kaur, Amandeep Kaur Image Compression Using Wavelet and Wavelet Packet Transformation IJCST Vol. 1, Issue 1, September 2010. 